<원 저>

\title{
Korean red ginseng prevents ethanol-induced hepatotoxicity in isolated perfused rat liver
}

\author{
Hye-Min Park ${ }^{1,2, \uparrow}$, Shang-Jin Kim ${ }^{1,3, \uparrow}$, Hyeon-Kyu Go ${ }^{1,2}$, Gi-Beum Kim ${ }^{2,3}$, Sung-Zoo Kim ${ }^{2}$, \\ Jin-Shang Kim ${ }^{1,3}$, Hyung-Sub Kang ${ }^{1,2, *}$ \\ ${ }^{1}$ College of Veterinary Medicine, ${ }^{2}$ Center for Healthcare Technology Development, and \\ ${ }^{3}$ Korean Zoonoses Research Institute, Chonbuk National University, Jeonju 561-756, Korea
}

(Accepted: May 20, 2011)

\begin{abstract}
Alcohol abuse and its medical and social consequences are a major health problem in many areas of the world. Korean red ginseng (KRG) has been traditionally used for the treatment of liver disease. This study was conducted to evaluate the hepatoprotective effects of KRG against hepatotoxicity in SpragueDawley rats treated with ethanol $(\mathrm{EtOH})$. Administration of $\mathrm{EtOH}$ for 20 days induced significant changes in serum biochemical parameters (aspartate aminotransferase, alanine transaminase, and glucose) accompanied by histological changes in the liver tissue. Treatment with KRG prior to administration of $\mathrm{EtOH}$ inhibited the EtOH-induced biochemical and histological changes of the liver. In perfused rat livers, administration of EtOH caused an increase in lactate dehydrogenase (LDH) release into the perfusate and activated the pro-apoptotic Bax protein but inhibited the anti-apoptotic Bcl-2 protein. Pretreatment with KRG prior to administration of $\mathrm{EtOH}$ decreased the EtOH-induced LDH release and inhibition of Bcl-2 protein. These results suggest that KRG exerts anti-apoptotic effects and alleviated EtOH-induced liver injury in rats.
\end{abstract}

Keywords : ethanol, ginseng, liver, liver perfusion, rat

\section{Introduction}

Alcoholism, as the major cause of liver cirrhosis, fatty liver, and alcoholic hepatitis, is a leading cause of morbidity and mortality throughout the world [18, 22]. The pathogenesis of these hepatic diseases is known to be related to programmed cell death, or apoptosis [17]. It has been shown that an increase in the number of apoptotic cells in the liver correlates with the development of ethanol (EtOH)-induced pathologic liver injury [15].

Some phytodrugs and extracts prepared from medicinal plants have proven hepatoprotective properties when used in the treatment of liver diseases such as hepatitis, cirrhosis, steatosis, and chemical-induced liver injury [3]. Korean ginseng (Panax ginseng, C.A. Meyer) is one of the most widely used medicinal plants and has a wide range of pharmacological and physiological actions [9]. Red ginseng ( $\mathrm{RG}$ ) is Panax ginseng that has been heated, either through steaming or sun-drying. During the production process of RG chemical transformations

*Corresponding author

Tel: +82-63-270-3883, Fax: +82-63-270-3780

E-mail: kang-hs@jbnu.ac.kr

${ }^{\dagger}$ The first two authors equally contributed to this study. of active physiological properties occur involving ginsenosides, polysaccharides, peptides, polyacetylenic alcohols, and fatty acids [19]. Korean RG (KRG) has been traditionally used for the treatment of various maladies including liver disease. In animal experiments, KRG was able to partially reverse the hepatotoxicity induced by carbon tetrachloride in rats [7] and inhibit increases in serum glutamic oxaloacetic transaminase and serum glutamic pyruvic transaminase levels in a rat model of acute hepatitis [14].

The present study investigated the protective effect of $\mathrm{KRG}$ on EtOH-induced hepatotoxicity in an ex vivo isolated liver model and an acute EtOH-induced liver injury model in rats.

\section{Materials and Methods}

\section{Animals and drug administration}

KRG extract obtained from red ginseng manufactured from the fresh roots of six-year-old Panax ginseng plants 
whose botanical identity had been verified was provided by the Korea Ginseng Corporation (Korea). Red ginseng was extracted seven times with 10 volumes of distilled water at $85^{\circ} \mathrm{C}$ for $8 \mathrm{~h}$ followed by cooling. The aqueous extract was combined, and then concentrated twice under vacuum at $40^{\circ} \mathrm{C}$.

Male Sprague-Dawley rats weighing 180 220 g were used for the in vivo experiment. The animals were purchased from Koatech (Korea) and housed for one week under controlled humidity (60 70\%) and temperature $\left(25 \pm 1^{\circ} \mathrm{C}\right)$ conditions prior to experimentation. All experimental protocols were approved by the Committee on the Care of Laboratory Animal Resources, Jeonbuk National University (Korea), and conducted in accordance with the Guide [16]. The rats had free access to a standard rat pellet diet and tap water. The animals were randomly assigned to three equal groups $(n=8$, per group) as follows: normal control, EtOH, or $\mathrm{KRG}+\mathrm{EtOH}$. The daily dose of KRG was $100 \mathrm{mg} / \mathrm{kg}$ and the other groups received an equal volume of vehicle. The selected dose of KRG was based on previous work $[1,8,20]$. EtOH groups were administered EtOH ( $3 \mathrm{~g} / \mathrm{kg}$ body weight, $30 \% \mathrm{v} / \mathrm{v}$ ) orally one hour after KRG or vehicle over 20 consecutive days. Six hours after the final EtOH treatment, animals were anesthetized by intraperitoneal injection of tiletamine/ zolazepam (Zoletile, $40 \mathrm{mg} / \mathrm{kg}$ ). Blood was collected in tubes containing the anticoagulant sodium heparin (5 IU/ $\mathrm{mL}$ ). Serum was separated by centrifugation at $3,000 \mathrm{rpm}$ for $20 \mathrm{~min}$ and analyzed for aspartate aminotransferase (AST), alanine transaminase (ALT), and glucose levels using an autoanalyzer Model 7020 (Hitachi, Japan).

\section{Histopathology}

The liver was excised for histopathological examination. Portions of the same lobe of liver from each animal were immediately fixed in $10 \%$ formaldehyde, embedded in paraffin, cut into $5 \sim 6 \mu \mathrm{m}$ sections, stained with hematoxylin-eosin (H\&E), and observed under a light microscope $(\times 400)$.

\section{Lactate dehydrogenase (LDH) measurement and}

\section{liver perfusion}

Male Sprague-Dawley rats weighing 250 280 g were used for the ex-vivo experiment. The animals were purchased from Koatech (Korea) and had free access to a standard rat pellet diet and tap water until $16 \mathrm{~h}$ before surgery at which time the food but not the water was removed. Excision of the liver and its connection to a recirculating perfusion system was performed as previously described [23]. After removal of the livers, rats were euthanized by exsanguination. The albumin- and serum-free perfusion medium consisted of oxygenated modified Krebs-Henseleit (KH) buffer containing 120 $\mathrm{mM} \mathrm{NaCl}, 3.5 \mathrm{mM} \mathrm{KCl}, 1.8 \mathrm{mM} \mathrm{CaCl}_{2}, 1.1 \mathrm{mM} \mathrm{MgCl}_{2}$, $1.2 \mathrm{mM} \mathrm{KH}_{2} \mathrm{PO}_{4}, 12 \mathrm{mM} \mathrm{NaHCO}_{3}, 10 \mathrm{mM}$ glucose, and $2 \mathrm{mM}$ Na-pyruvate; $\mathrm{pH}$ was adjusted to $7.4 \pm 0.02$ using $10 \mathrm{mM}$ Tris-base and $10 \mathrm{mM}$ Tris-acid. The buffer was gassed with $95 \% \mathrm{O}_{2}$ and $5 \% \mathrm{CO}_{2}$ and the temperature was maintained at $36.5 \pm 0.5^{\circ} \mathrm{C}$. Perfusion was performed under conditions of constant pressure $\left(240 \mathrm{~mm} \mathrm{H}_{2} \mathrm{O}\right)$ throughout the experiment and the perfusion flow rate was regulated at $10 \mathrm{~mL} / \mathrm{min}$ using a peristaltic pump. For LDH measurements, samples of $1 \mathrm{~mL}$ were taken from the perfusate every minute. After $20 \mathrm{~min}$ of perfusion to stabilize the liver, treatment was initiated. Perfusion with $\mathrm{KH}$ buffer for an additional $10 \mathrm{~min}$ was performed as a control. Livers were perfused with $\mathrm{KH}$ buffer containing $1 \% \mathrm{EtOH}$ for $10 \mathrm{~min}$. KRG $(100 \mu \mathrm{g} / \mathrm{mL})$ was added to $\mathrm{KH}$ buffer, which was perfused $5 \mathrm{~min}$ before $\mathrm{EtOH}$ administration. The concentration of EtOH used was selected based on previously reports which showed that it were capable of inducing hepatotoxic injury [24]. Samples from the perfusate were used to measure LDH activity by the established chemical-based colorimetric method, in which generated pyruvic acid is quantified using a spectrophotometer (SpectraMax fluorometer with a SoftMax Programme; Molecular Probes, USA) at a wavelength of $490 \mathrm{~nm}$. At the end of the experiments liver samples were frozen in liquid nitrogen until further analysis.

\section{Western blot analysis of Bcl-2 and Bax}

Frozen liver samples $(100 \mathrm{mg})$ were suspended in 1 $\mathrm{mL}$ of an ice-cold solution containing $250 \mathrm{mM}$ sucrose, $30 \mathrm{mM}$ histidine, $1 \mathrm{mM}$ EDTA, $1 \mathrm{mM}$ phenylsulfonyl fluoride, $23 \mathrm{mg}$ aprotinin, $50 \mathrm{mg}$ leupeptin, $0.25 \mathrm{mM}$ dithiothreitol, and 1\% Triton X-100 (pH 6.8). The tissue was immediately homogenized and the extract transferred to a $1.5 \mathrm{~mL}$ microfuge tube on ice. The sample was then sonicated using an ultrasonic processor (Sonics \& Materials, USA) and $0.5 \mathrm{~mL}$ was microcentrifuged at $14,000 \mathrm{rpm}$ for $30 \mathrm{~min}$. The protein in $30 \mu \mathrm{L}$ of the resulting supernatant was resolved with $7.5 \%$ sodium dodecyl sulfate-polyacrylamide gel electrophoresis (SDSPAGE). The resolved protein was electrotransferred to a Hybond-ECL nitrocellulose membrane blocked with 


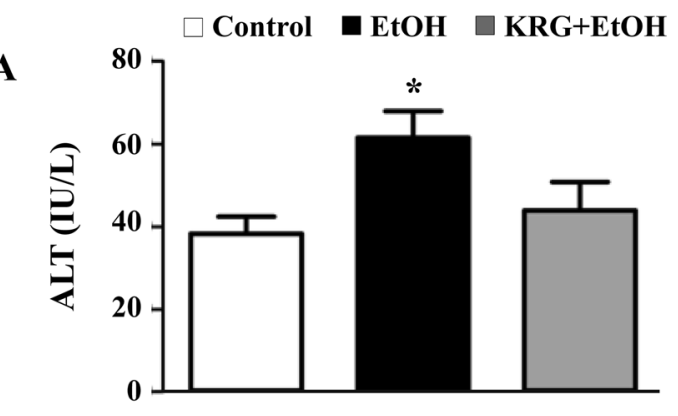

B

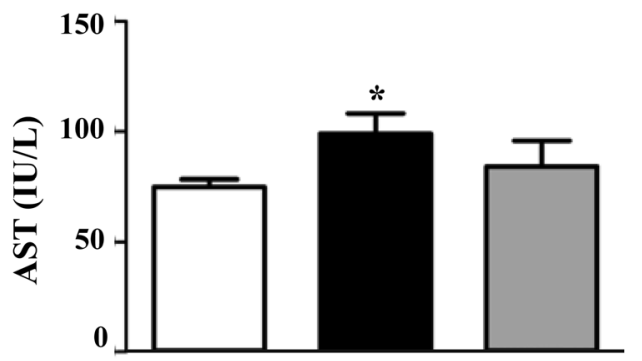

C

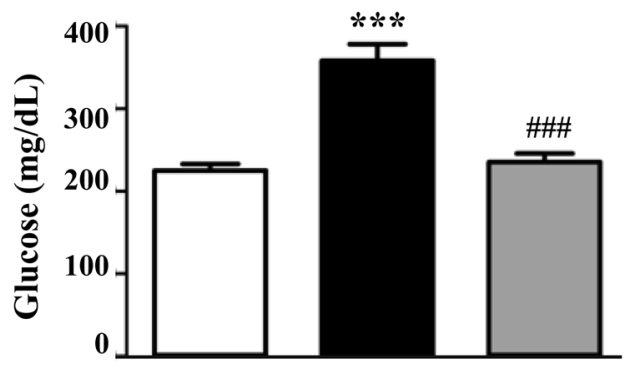

Fig. 1. Effects of Korean red ginseng (KRG) on serum biochemical levels in rats with ethanol $(\mathrm{EtOH})$-induced liver injury. The data are reported as mean $\pm \mathrm{SE}(\mathrm{n}=8)$ for each group. ${ }^{*} p<0.5,{ }^{* * *} p<0.001$ vs. control, ${ }^{\# \#} p<0.001 v$ s. $\mathrm{EtOH}$.

Tris-buffered saline (20 mM Tris and $140 \mathrm{mM} \mathrm{NaCl}, \mathrm{pH}$ 7.6) containing $0.1 \%$ Tween 20 (TBST) and $5 \%$ milk at room temperature for $2 \mathrm{~h}$. The membrane was then incubated overnight with a monoclonal antibody (primary antibody; Bcl-2, Bax, $\beta$-actin; Cell Signaling Technology, USA) at a $1: 1000$ dilution in TBST with $5 \%$ milk at $4^{\circ} \mathrm{C}$. The blots were washed in TBST three times for 5 min each time, and the bands were detected using enhanced chemiluminescence. Blots were quantified using laser scanning densitometry (Bio-Rad Laboratories, USA).

\section{Statistical analysis}

The data were analyzed using $t$ tests and repeated measures of analysis of variance (ANOVA) followed by a Bonferroni correction. The results are expressed as the
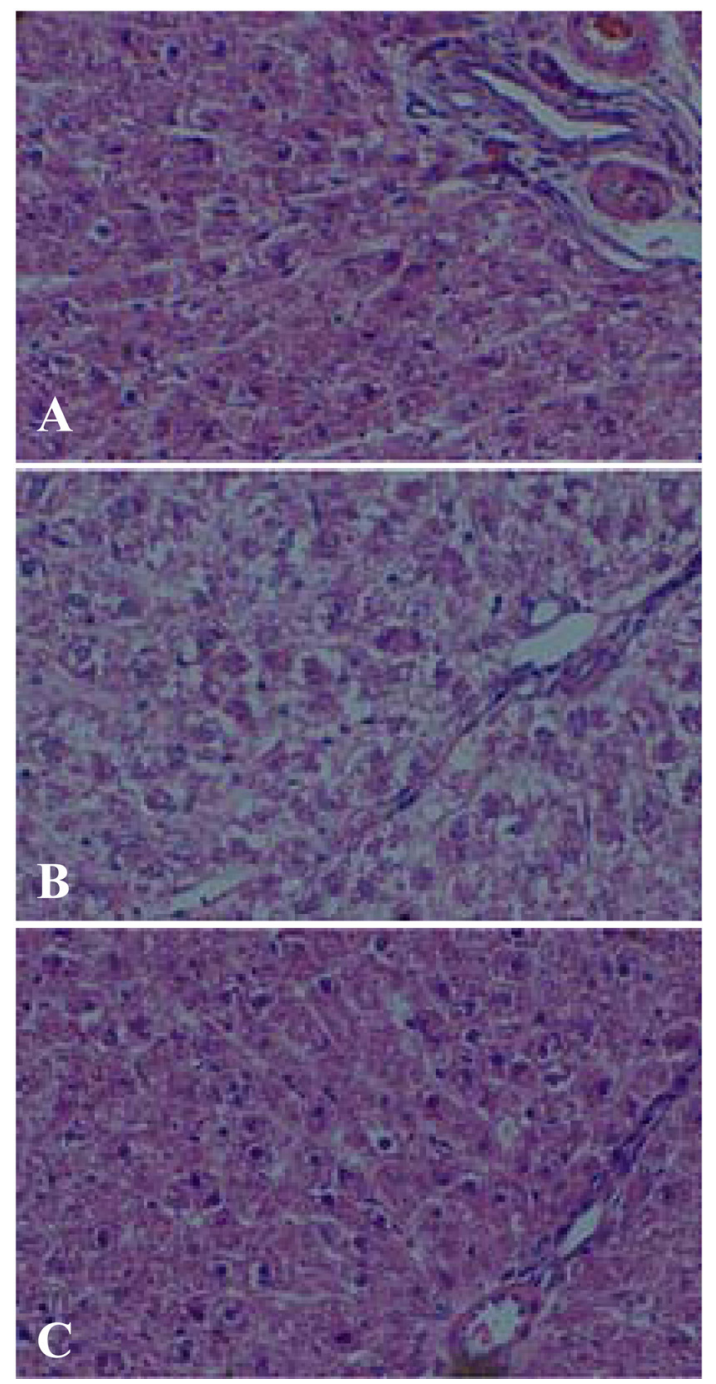

Fig. 2. Light microscopic analysis of liver sections of normal and EtOH-treated rats with or without KRG administration. (a) Control, (b) $\mathrm{EtOH}$, (c) $\mathrm{KRG}+\mathrm{EtOH}$.

mean $\pm \mathrm{SE}$ of the mean. $P$-values $<0.05$ were considered significant.

\section{Results}

\section{Serum enzyme parameters in EtOH-induced rat liver injury}

The serum levels of ALT, AST, and glucose were used as biochemical markers for hepatic damage. Compared to the control group, the EtOH treated group showed a significant increase in serum AST, ALT, and glucose levels (AST: $75.0 \pm 3.4 \mathrm{IU} / \mathrm{L}$ vs. $99.0 \pm 9.2 \mathrm{IU} / \mathrm{L}$, ALT: 
A

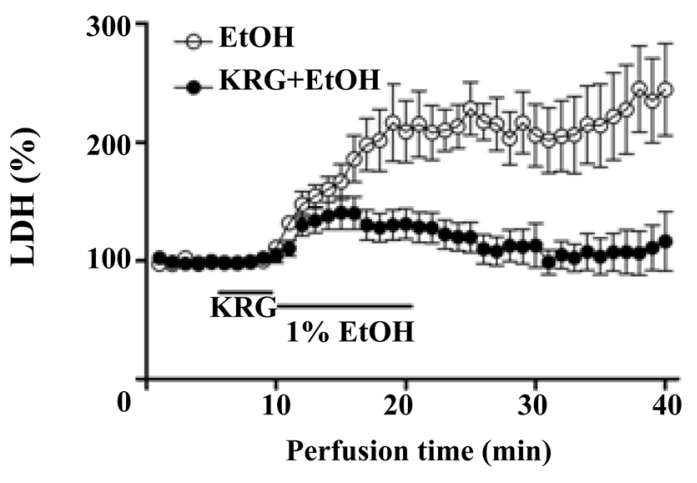

B

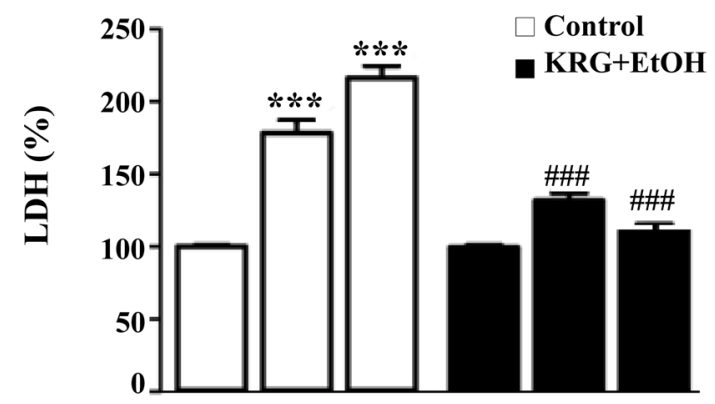

Fig. 3. Lactate dehydrogenase (LDH) release into the perfusate. (a) Time course of LDH release from isolated rat livers as influenced by the addition of $\mathrm{EtOH}$ with and without KRG. (b) Levels of LDH released into the perfusate after addition of $1 \% \mathrm{EtOH}$ without $\square$ and with $\square \mathrm{KRG}$ pretreatment $(100 \mathrm{~g} / \mathrm{mL})$. The data is reported as the mean \pm SE of five different preparations. ${ }^{* * *} p<0.001$ vs. control, $\# p<0.001$ vs. $\mathrm{KRG}+\mathrm{EtOH}$ group.

$38.4 \pm 4.1 \mathrm{IU} / \mathrm{L}$ vs. $61.6 \pm 6.4 \mathrm{IU} / \mathrm{L}$, glucose: $225.0 \pm 8.1$ $\mathrm{mg} / \mathrm{dL}$ vs. $358.3 \pm 19.7 \mathrm{mg} / \mathrm{dL})$. Co-administration of KRG tended to reduce serum AST, ALT, and glucose to nearly control levels (AST: 75.0 $\pm 5.2 \mathrm{IU} / \mathrm{L}, \mathrm{ALT}: 40 \pm 4.2 \mathrm{IU} /$ $\mathrm{L}$, glucose: $235.4 \pm 10.5 \mathrm{mg} / \mathrm{dL}$ ).

\section{Histologic analysis}

Microscopic examination of the liver sections of the control animals showed normal architecture of hepatic lobules in the form of hepatocytes arranged from the portal vein (Fig. 2a). Examination of rat livers from the group treated with EtOH showed swelling, slight hydropic degeneration, and lipid changes of hepatocytes (Fig. 2b). Histopathological changes induced by $\mathrm{EtOH}$ were remarkably improved by co-administration of KRG (Fig. 2c).

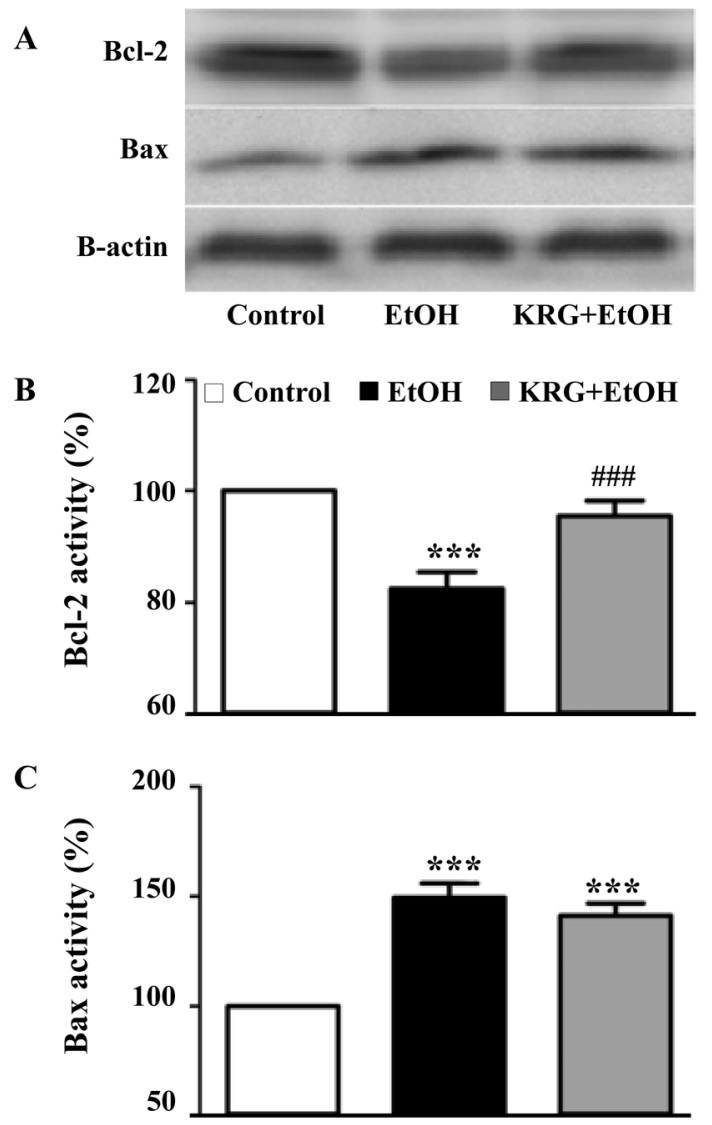

Fig. 4. Effects of EtOH and KRG on Bcl-2 family proteins in isolated perfused rat livers. Immunoprecipitation of Bcl2 and Bax under EtOH loading in perfused rat livers. Livers were perfused with $1 \% \mathrm{EtOH}$ for $30 \mathrm{~min}$. Prior to $\mathrm{EtOH}$ loading, livers were pretreated with or without $100 \mu \mathrm{g} / \mathrm{mL}$ KRG. (a) The amount of Bcl-2 and Bax were measured by Western blot analysis. This picture shows the typical changes in Bcl-2 and Bax in a perfused rat liver. (b) Blots were quantified by laser scanning densitometry. The data are reported as mean $\pm \mathrm{SE}$ of five different preparations. ${ }^{* * *} p<0.001$ vs. control, ${ }^{\# \#} p<0.001$ vs. EtOH.

\section{Effects of EtOH and KRG on LDH release in per- fused rat liver}

We measured LDH release from isolated rat liver in the presence of $1 \% \mathrm{EtOH}$ with and without KRG (100 $\mathrm{mg} / \mathrm{kg}$ body weight). As shown as Fig. 3, administration of $\mathrm{EtOH}$ for $10 \mathrm{~min}$ resulted in significant increase in LDH release (during $10 \mathrm{~min}$ of $\mathrm{EtOH}$ administration; $p$ $<0.001$ compared to control, during $20 \mathrm{~min}$ of wash-out; $p<0.001$, Bonferroni post hoc test following one-way ANOVA). Pretreatment with KRG $5 \mathrm{~min}$ prior to administration of $\mathrm{EtOH}$ produced a remarkable attenuation 
in elevated levels of LDH (during $10 \mathrm{~min}$ of $\mathrm{EtOH}$ administration; $p<0.001$ compared to the administration of EtOH per se, during 20 min of wash-out; $p<0.001$, Bonferroni post hoc test following two-way ANOVA).

\section{Effects of EtOH and KRG on Bcl-2 family pro- teins in perfused rat livers}

To evaluate the effects of EtOH on the production of apoptotic proteins, we measured activity of $\mathrm{Bcl}-2$ and Bax in the perfused livers following the LDH release experiments. The administration of $1 \% \mathrm{EtOH}$ induced significant Bax activation and Bcl-2 inhibition (Fig. 4). Pretreatment with KRG (100 mg/kg body weight) $5 \mathrm{~min}$ prior to administration of EtOH counteracted $\mathrm{EtOH}-$ induced Bcl-2 inhibition. Using densitometry, the percent variations in the EtOH treated group $(n=4)$ compared to the control group (100\%) were determined to be 149.4 $\pm 6.5 \%$ (Bax protein) and $82.5 \pm 2.9 \%$ (Bcl-2 protein), and those of the KRG+EtOH group were $141.2 \pm 5.6 \%$ (Bax protein) and $95.5 \pm 2.7 \%$ (Bcl-2 protein).

\section{Discussion}

Chronic alcohol consumption has been associated with excessive blood glucose levels. It can reduce the body's responsiveness to insulin and cause glucose intolerance in healthy individuals [21] and alcoholics with liver cirrhosis [13]. In this study, rats treated with EtOH for 20 days had significantly increased blood glucose levels and pathological changes were observed in their livers. The obvious indicator of liver injury is leakage of cellular enzymes into plasma [2]. We confirmed an increase in serum enzymes levels associated with ALT and AST in EtOH-treated rats, indicating enhanced permeability, injury, and necrosis of hepatocytes [4].

Korean ginseng is one of the most widely used medicinal plants, particularly in traditional oriental medicine. Previous studies have suggested that ginseng extracts bestow a pronounced hepatoprotective effect, assessed through the activity of transaminases (AST, ALT) following hepatotoxicity in rats treated with chromium VI [1]. Also, RG has been shown to accelerate the rate of liver regeneration and ameliorate liver injury after partial hepatectomy in dogs [12]. In the present study, co-administration of KRG alleviated liver damage and inhibited the increases in glucose, ALT, and AST levels caused by EtOH.

In perfused rat livers, administration of EtOH caused liver cell membrane damage as evidenced by an unreversible significant increase in LDH release into the perfusate. Pretreatment with KRG prior to administration of EtOH reduced LDH release. Thus, KRG inhibited the cell membrane damage induced by $\mathrm{EtOH}$.

Short-term EtOH intoxication causes mitochondrial dysfunction [10], and apoptosis [6, 11] in primary cultures of rat hepatocytes. During apoptosis, pro-apoptotic proteins of the Bcl-2 family, including Bax, Bim, and Bid, can translocate to the outer membrane of mitochondria and induce apoptosis [26]. In contrast, anti-apoptotic proteins in this family, including Bcl-2, sequester in the mitochondria and prevent apoptosis [5, 25]. The present results indicate that the administration of EtOH to perfused rat livers activates the pro-apoptotic Bax protein but inhibits the anti-apoptotic Bcl-2 protein. Pretreatment with KRG prior to the administration of EtOH reduced the EtOH-induced inhibition of Bcl-2 protein. Although pretreatment with KRG reduced activation of Bax protein, there was no significant difference. Therefore, it appears that the protective effect of KRG against EtOH-induced hepatic injury may be regulated by mitochondrial intracellular stress signaling.

\section{Conclusion}

These results suggest that KRG has potent hepatoprotective activity against EtOH-induced hepatic injury in rats. Since KRG may possess anti-apoptotic activity and ameliorate hepatic injury induced by $\mathrm{EtOH}$, the current data may be useful in the development of therapeutic strategies to ameliorate or prevent the toxic effects of alcohol.

\section{Acknowledgments}

This research was supported by a grant (2009) from the Korean Society of Ginseng funded by Korea Ginseng Corporation. The extract of KRG used in this study was supplied by the Korea Ginseng Corporation.

\section{References}

1. Abdel-Wahhab MA, Ahmed HH. Protective effect of Korean Panax ginseng against chromium VI toxicity and free radicals generation in rats. J Ginseng Res 2004, 28, 11-17.

2. Baldi E, Burra P, Plebani M, Salvagnini M. Serum 
malondialdehyde and mitochondrial aspartate aminotransferase activity as markers of chronic alcohol intake and alcoholic liver disease. Ital J Gastroenterol 1993, 25, 429-432.

3. Chidambara Murthy KN, Jayaprakasha GK, Singh RP. Studies on antioxidant activity of pomegranate (Punica granatum) peel extract using in vivo models. J Agric Food Chem 2002, 50, 4791-4795.

4. Goldberg DM, Watts C. Serum enzyme changes as evidence of liver reaction to oral alcohol. Gastroenterology 1965, 49, 256-261.

5. Gómez-Lechón MJ, O'Connor E, Castell JV, Jover R. Sensitive markers used to identify compounds that trigger apoptosis in cultured hepatocytes. Toxicol Sci 2002, 65, 299-308.

6. Higuchi H, Adachi M, Miura S, Gores GJ, Ishii H. The mitochondrial permeability transition contributes to acute ethanol-induced apoptosis in rat hepatocytes. Hepatology 2001, 34, 320-328.

7. Jeong TC, Kim HJ, Park JI, Ha CS, Park JD, Kim SI, Roh JK. Protective effects of red ginseng saponins against carbon tetrachloride-induced hepatotoxicity in Sprague Dawley rats. Planta Med 1997, 63, 136-140.

8. Kim YH, Kim GH, Shin JH, Kim KS, Lim JS. Effect of Korean red ginseng on testicular tissue injury after torsion and detorsion. Korean J Urol 2010, 51, 794-799.

9. Ko RJ. Adulterants in Asian patent medicines. N Engl J Med 1998, 339, 847.

10. Kurose I, Higuchi H, Kato S, Miura S, Watanabe N, Kamegaya Y, Tomita K, Takaishi M, Horie Y, Fukuda M, Mizukami K, Ishii H. Oxidative stress on mitochondria and cell membrane of cultured rat hepatocytes and perfused liver exposed to ethanol. Gastroenterology 1997, 112, 1331-1343.

11. Kurose I, Higuchi H, Miura S, Saito H, Watanabe N, Hokari R, Hirokawa M, Takaishi M, Zeki S, Nakamura T, Ebinuma H, Kato S, Ishii H. Oxidative stress-mediated apoptosis of hepatocytes exposed to acute ethanol intoxication. Hepatology 1997, 25, 368-378.

12. Kwon YS, Jang KH, Jang IH. The effects of Korean red ginseng (Ginseng Radix Rubra) on liver regeneration after partial hepatectomy in dogs. J Vet Sci 2003, 4, 83-92.

13. Letiexhe MR, Scheen AJ, Gérard PL, Bastens BH, Pirotte J, Belaiche J, Lefèbvre PJ. Insulin secretion, clearance, and action on glucose metabolism in cirrhotic patients. J Clin Endocrinol Metab 1993, 77, 1263-1268.

14. Matsuda H, Samukawa K, Kubo M. Anti-hepatitic activity of ginsenoside Ro. Planta Med 1991, 57, 523526.

15. Nanji AA, Zakim A. Alcoholic liver disease. In: Zakim D, Boyer TD (eds.). Hepatology: A Textbook of Liver Disease. 3rd ed. pp. 891-961, WB Saunders, Philadelphia, 1996.

16. National Research Council. Guide for the Care and Use of Laboratory Animals. NIH Publication No. 8523. National Academy Press, Washington, 1996.

17. Natori S, Rust C, Stadheim LM, Srinivasan A, Burgart LJ, Gores GJ. Hepatocyte apoptosis is a pathologic feature of human alcoholic hepatitis. J Hepatol 2001, 34, 248-253.

18. Niemelä $\mathbf{O}$, Parkkila S, Ylä-Herttuala S, Vilanuera J, Ruebner B, Halsted CH. Sequential acetaldehyde production, lipid peroxidation, and fibrogenesis in micropig model of alcohol-induced liver disease. Hepatology 1995, 22, 1208-1214.

19. Park JD. Recent studies on the chemical constituents of Korean ginseng (Panax ginseng C.A. Meyer). Korean J Ginseng Sci 1996, 20, 389-415.

20. Seong GS, Chun SG, Chang CC. Hepatoprotective effects of white and red ginseng extracts on acetaminophen-induced hepatotoxicity in mice. J Ginseng Res 2005, 29, 131-137.

21. Shah JH. Alcohol decreases insulin sensitivity in healthy subjects. Alcohol Alcohol 1988, 23, 103-109.

22. Shimamatsu K, Wanless IR. Role of ischemia in causing apoptosis, atrophy, and nodular hyperplasia in human liver. Hepatology 1997, 26, 343-350.

23. Strubelt O, Younes M, Pentz R. Influence of extracellular calcium on allyl alcohol-induced hepatotoxicity. Acta Pharmacol Toxicol (Copenh) 1986, 59, 47-52.

24. Tessman PA, Romani A. Acute effect of EtOH on $\mathrm{Mg}^{2+}$ homeostasis in liver cells: evidence for the activation of an $\mathrm{Na}^{+} / \mathrm{Mg}^{+}$exchanger. Am J Physiol Gastrointest Liver Physiol 1998, 275, G1106-1116.

25. Tsujimoto Y, Shimizu S. Bcl-2 family: life-or-death switch. FEBS Lett 2000, 466, 6-10.

26. Yang E, Zha J, Jockel J, Boise LH, Thompson CB, Korsmeyer SJ. Bad, a heterodimeric partner for Bcl$\mathrm{x}_{\mathrm{L}}$ and Bcl-2, displaces Bax and promotes cell death. Cell 1995, 80, 285-291. 